\title{
Antinociceptive effect of Pleurotus ostreatus (Oyster Mushroom) Aqueous Extracts in Rattus norvegicus (Albino Rats)
}

\author{
*11ZITTE, LF; KONYA, RS \\ Department of Animal and Environmental Biology, Faculty of Science, University of Port Harcourt, Nigeria. \\ Correspondence Author; Leelee.zitte@ uniport.edu.ng, lefzy@yahoo.com, +234-8037971401, +234-8079756415
}

\begin{abstract}
Antinociceptive is reducing sensitivity to painful stimuli for the individual. The objective of this study was to evaluate the antinociceptive potentials of graded doses of Pleurotus ostreatus (Oyster Mushroom) aqueous extract in Rattus norvegicus (Albino Rats) and its chemical pattern by comparing it with a standard drug and a control using the hot water based flick tail test. Thirty five adult rats of both sexes were used for the experiment which, were divided into five groups of seven rats per group. Group one was used as the control (with $1 \mathrm{ml}$ normal saline), while groups two, three and four were treated with 100,200 and $400 \mathrm{mg} / \mathrm{kg}$ of Pleurotus ostreatus aqueous extracts and group five treated with $15 \mathrm{mg} / \mathrm{kg}$ Aspirin (a standard drug) as positive control. Hot water at $55^{\circ} \mathrm{C}$ was used to determine the nociceptive responses of the animals to detect anti-nociceptive effects of Pleurotus ostreatus extracts as compared to the control in hot water inflicted pain. The results suggested that Pleurotus ostreatus aqueous extract exhibits antinociceptive properties against thermal stimulus at $55^{\circ} \mathrm{C}$. The diversity of individual animals' pain tolerance threshold when immersed in hot water was also observed during the experiment. However, the extract indicated a high degree of anti-nociceptive effect at 30,60, 90 and 120 minutes post treatment period, with a progressively longer threshold time for pain sensitivity. It was also found that at 90 minute period, the control portrayed a relatively short response time. (c) JASEM
\end{abstract}

http://dx.doi.org/10.4314/jasem.v20i2.31

KEY WORDS: Anti-nociceptive, threshold pain, Pleurotus ostreatus, hot water test flick tail.

Pain is an irritating or detestable sensory and emotional experience linked with a damaged tissue or a potentially damaged tissue. It is a feeling related to such experience as burning a finger or putting iodine on injury (Harold, 1964). It motivates us to withdraw from damaging or potentially damaging condition, it protects the damaged body part while it is healing, and guard against such situation in the future (Bernston and Cacioppo 2007, Lynn 1983).

Because of the importance of pain sensitivity to life, insensitive individuals to certain pains can lead to some dangerous and life threatening circumstances. Those with insensitivity to pain may repeat the painful process hence having damaging consequences for not avoiding painful conditions (Nikola, 2001). Indifference to pain is rarely congenital; people expressing this have normal nerves on medical investigations, and find pain unpleasant, but do not avoid repetition of the pain stimulus (Nagasako, 2003).

Abnormalities in the nervous system may also cause Insensitivity to pain. It may be as a result of nervous system damages like the spinal cord injury. It could also be as a result of diseases like diabetes mellitus (diabetic neuropathy) or leprosy (Brand and Yancey 1997).

Woolf (2010) suggests three classes of pain namely: (1) nociceptive pain, (caused by stimulation of peripheral nerve fibers that respond only to stimuli approaching or exceeding harmful intensity (nociceptors), (2) inflammatory pain (associated with tissue damage and the infiltration of immune cells), and (3) pathological pain (a disease state caused by damage to the nervous system or by its abnormal function e.g. fibromyalgia, irritable bowel syndrome, tension type headache, etc).

Nociceptive pain is further classified into three classes according to the mode of noxious stimulation. These classes are thermal (e.g. heat or cold), mechanical (e.g. crushing, tearing, shearing, etc.) and chemical (e.g. iodine in a cut, pepper in the eyes).

Pain is also established with regards to the thresholds. Pain thresholds are measured by gradually increasing the intensity of a stimulus such as electric current or heat applied to the body. The pain perception threshold 
is established at a point where the stimulus begins to hurt while the pain tolerance threshold is reached when the subject acts to stop the pain.

In humans, the most reliable method of assessing pain is by asking questions, but in animals it is not so. Animals do not answer questions directly like humans on how much they feel pains thus the criteria for pain assessment in humans cannot be used for animals (Rollin 1985). He argued that researchers remained unsure into the $1980 \mathrm{~s}$ as to whether animals experience pains and that veterinarians trained in the United States before 1989 were simply taught to ignore animals pains (Rollin, 1989).

Pleurotus spp known to be an edible mushroom is also found to have some medicinal properties. Pleurotus florida is observed to possess antioxidant, immunostimulating, antitumor, anti-inflammatory and anticataract properties. (Roy et al., 2009, Jose et al., 2004). It was reported after an in vitro experiment by Ganeshpurkar et al., (2011), and (Ganeshpurkar et al., (2012) that mushroom was also seen to be a good source of Phenolic and flavonoids that are suggested to be responsible for anthelmintic potentials they also have anti-inflammatory properties. American oyster mushroom have also be found to have some antinociceptive activities (Vasudewa et al., 2007).

The objective of this study was to evaluate the antinociceptive activities of graded doses of Pleurotus ostreatus (Oyster Mushroom) aqueous extract in Rattus norvegicus (Albino Rats) to confirm its potential analgesic properties.

\section{MATERIALS AND METHODS}

Pleurotus ostreatus fruiting body was purchased from mushroom house, Faculty of Agriculture Demonstration Farms, University of Port Harcourt, Port Harcourt, Nigeria. It was developed through the process of tissue culture and spawn production to get mycelium mass which was used to produce the experimental fruiting bodies.

The animals (Rattus norvegicus) (thirty-five) were purchased from the Animal House, Department of Animal and Environmental Biology Choba Campus. They were divided into five groups of seven animals per group and kept in plastic cages, for two week to acclimatize to the laboratory experimental condition. During this period, they were covered with wire gauze, and wood shaven used as bedding material. Clean drinking water and feed were provided ad libitum.

Mushroom fruiting body was dried and pulverized in electric grinder. $500 \mathrm{~g}$ of the pulverized mushroom was macerated in distilled water for 24 hours. After the 24 hours, the aqueous sample was decanted and filtered through the whatman filter paper. The filtrate was measured and placed in a rotary evaporator for dewatering and concentration of the extract. It was further concentrated, in the rotary evaporator, a sample was measured and evaporated to dryness in an oven at a temperature of $105^{\circ} \mathrm{C}$ to have the weight of the dry extract. This was aimed at guarding against the loss of essential constituents as a result of high heat on the whole sample. The dry weight of the extract was then determined with a simple ratio.

$$
\text { Percentage moisture } \quad=\frac{W 1-W 2}{W 1} X \frac{100}{1}
$$

Where

$\mathrm{W} 1=$ weight of wet sample

$\mathrm{W} 2=$ weight of dry sample

The determined percentage was used to calculate the dry weight of the working extract.

The rats were between the weights of $230 \mathrm{~g}$ and $270 \mathrm{~g}$, so with a mean weight of $250 \mathrm{~g}$, the $\mathrm{mg} / \mathrm{kg}$ body weight was determined.

The extract was administered orally at concentrations of 100,200 , and $400 \mathrm{mg} / \mathrm{kg}$ to groups 2, 3 and 4 , while group 5 was orally treated with $15 \mathrm{mg} / \mathrm{kg}$ of Aspirin as a standard drug and group one used as the control.

The tail flick test was conducted according to the method of D'Amour and Smith (1941). The animals were fasted overnight, and grouped according to their treatments. Each animal was identified with a label. Tails of the animals were dipped in a flask containing hot water at $55^{\circ} \mathrm{C}$ and immediately the stop watch started. The moment the animals flicked the tail, the stopwatch was stopped and the time recorded. The process was repeated thrice to get an average response time for each animal at a water temperature of $55^{\circ} \mathrm{C}$. After that the animals were administered the treatments according to their groups. Hot water test was then conducted after every thirty minutes (30 mins) for two hours.. With the aid of a thermometer, a hot vacuum flask and a heating source, a constant temperature of $55^{\circ} \mathrm{C}$ was maintained for the experiment.

Statistical analysis was by the method of analysis of variance (ANOVA) to compare results within the different groups and with the control. The significant difference was evaluated using the method of Duncan in a post hoc comparison test. Statistical analysis were carried out using version 16 of SPSS (IBM). Data were 
presented as means \pm standard error of mean with significant difference at $\mathrm{p}-\leq 0.05$.

\section{RESULTS AND DISCUSSION}

Result of flick tail test, according to the different treatments and different time lags were observed. The result shows that the baseline mean pain tolerance threshold time (MPTTT) for the animals was $2.77 \pm$ $0.40 \mathrm{~s}$ which demonstrated that they all had similar pain tolerance threshold time (PTTT). However at repeated tests, the PTTT increased, (even among control group, their PTTT increased to $3.42 \pm 0.53$ $\mathrm{s})$. The treatment groups expressed remarkable difference in the PTTT as compared with baseline test
(0 minutes tests), and the control at 120 minutes interval. Statistically, there was no significant difference $(p>0.05$.) among the different groups before treatment (baseline test) and at $30 \mathrm{~min}$ post treatment time. However at the $60 \mathrm{~min}$. and $90 \mathrm{~min}$., treatment 2-4 had significant difference $(p \leq 0.05$.) in PTTT with the control while treatment 1 did not have any significant difference in PTTT with the control and other treatments. At the 120 min period (two hours) the control was significantly different $(p \leq$ 0.05.) from all the treatments but the different treatment regime did not differ significantly $(p>0.05$. $)$. (Table 1)

Table 1 Mean pain tolerance threshold time (PTTT) (in seconds) at 30 minutes interval

\begin{tabular}{lccccc}
\multicolumn{5}{c}{ from the baseline } \\
\hline Treatments & $\begin{array}{c}\text { Baseline } \\
(0 \mathrm{~min})\end{array}$ & $30 \mathrm{~min}$ & $60 \mathrm{~min}$ & $90 \mathrm{~min}$ & $120 \mathrm{~min}$ \\
\hline Control & $2.87 \pm 0.44^{\mathrm{a}}$ & $3.10 \pm 0.51^{\mathrm{a}}$ & $3.10 \pm 0.66^{\mathrm{a}}$ & $3.03 \pm 0.29^{\mathrm{a}}$ & $3.42 \pm 0.53^{\mathrm{a}}$ \\
Treat $1100 \mathrm{mg} / \mathrm{kg}$ & $2.74 \pm 0.34^{\mathrm{a}}$ & $3.39 \pm 1.12^{\mathrm{a}}$ & $4.30 \pm 0.68^{\mathrm{a}}$ & $4.90 \pm 1.47^{\mathrm{ab}}$ & $6.45 \pm 2.15^{\mathrm{b}}$ \\
Treat $2200 \mathrm{mg} / \mathrm{kg}$ & $2.61 \pm 0.38^{\mathrm{a}}$ & $3.20 \pm 1.07^{\mathrm{a}}$ & $5.65 \pm 1.26^{\mathrm{b}}$ & $6.04 \pm 1.00^{\mathrm{b}}$ & $6.83 \pm 0.58^{\mathrm{b}}$ \\
Treat $3400 \mathrm{mg} / \mathrm{kg}$ & $2.82 \pm 0.46^{\mathrm{a}}$ & $3.22 \pm 0.44^{\mathrm{a}}$ & $5.09 \pm 1.11^{\mathrm{b}}$ & $5.24 \pm 1.94^{\mathrm{b}}$ & $6.49 \pm 1.81^{\mathrm{b}}$ \\
$15 \mathrm{mg} / \mathrm{Kg} \mathrm{Aspirin}$ & $2.78 \pm 0.43^{\mathrm{a}}$ & $4.09 \pm 0.96^{\mathrm{a}}$ & $5.24 \pm 1.13^{\mathrm{b}}$ & $5.98 \pm 1.47^{\mathrm{b}}$ & $6.75 \pm 2.14^{\mathrm{b}}$ \\
Total mean & $2.77 \pm 0.40$ & $3.40 \pm 0.89$ & $4.70 \pm 1.28$ & $5.04 \pm 1.69$ & $6.00 \pm 2.00$ \\
\hline
\end{tabular}

Values on the same column having the same superscript (a, ab, b, bc, c.) letter are not significantly different $(p>0.05$.)

The difference in pain tolerance threshold time in seconds and percentages were also analyzed. This was to enable us appreciate the extent of anti-nociceptive effect demonstrated by the extract on hot water induced pain.

The result expressed in percentage further revealed some hidden differences. It showed that at the $120 \mathrm{~min}$ mark, the control had $19.20 \%$ increase in PTTT compared to the baseline test ( at $0 \mathrm{~min}$ ) while treatment one (with $100 \mathrm{mg} / \mathrm{kg}$ ) had $134.88 \%$ increase in PTTT (more than double) compared to the result of the baseline test ( at $0 \mathrm{~min}$ ). Treatment two $(200 \mathrm{mg} / \mathrm{kg})$ had $161.56 \%$ increase in PTTT compared to the baseline time. Treatments three and positive control (400 $\mathrm{mg} / \mathrm{kg}$ and aspirin respectively) also had responses more than double the time taken by the baseline test to reach PTTT (Table 2).

Table 2. Difference in pain tolerance threshold time (in second) at

every 30 mins from the baseline time. Percentage in parenthesis $(\%)$

\begin{tabular}{|c|c|c|c|c|}
\hline Treatments & $30 \min (s)$ & $60 \min (s)$ & $90 \min (s)$ & $120 \min (s)$ \\
\hline Control & $0.23(\mathbf{8 . 1 1})$ & 0.36 (12.69) & $0.16 \quad(\mathbf{5 . 4 2})$ & $0.55(\mathbf{1 9 . 2 0})$ \\
\hline Treat1 (1 & $0.65(\mathbf{2 3 . 5 3})$ & $1.55(\mathbf{5 6 . 6 4 )}$ & 2.15 (78.29) & 34.88) \\
\hline Treat2 $(200 \mathrm{mg} / \mathrm{kg})$ & $0.58(\mathbf{2 2 . 3 6})$ & 3.04 (116.64) & $3.42(\mathbf{1 3 1 . 0 0})$ & $4.22(\mathbf{1 6 1 . 5 6})$ \\
\hline Treat3 (400 mg/kg) & $0.40(\mathbf{1 4 . 2 5})$ & $2.27(\mathbf{8 0 . 6 3})$ & $2.43(\mathbf{8 6 . 1 6})$ & $3.67(\mathbf{1 3 0 . 2 2})$ \\
\hline $15 \mathrm{mg} / \mathrm{Kg}$ Aspirin & $1.31(\mathbf{4 7 . 2 3})$ & $2.46(\mathbf{8 8 . 3 9})$ & $3.20(\mathbf{1 1 5 . 2 1})$ & $3.97(\mathbf{1 4 2 . 6 5 )}$ \\
\hline
\end{tabular}

The hot water flicking test result showed that there was an effect of the aqueous Pleurotus ostreatus extract on sensitivity of the animal to pain as expressed in the PTTT at every 30 minutes interval. Before treatment, the average time taken was $2.87 \mathrm{~s}$ in control while after $120 \mathrm{~min}$ it had an average PTTT of $3.42 \mathrm{~s}$. Treatment 3 showed a time of $2.82 \mathrm{~s}$ before treatment and $6.45 \mathrm{~s}$ after treatments. This difference was attributed to the analgesic effects (anti-nociceptive) of the aqueous extract of Pleurotus ostreatus when administered orally.

The average change in PTTT was well established in the treatments when they were compared with the control. this was because the control had the least change in PTTT as compared to the baseline time $(0.2329 \mathrm{~s}$ in $30 \mathrm{~min}$. and $0.5515 \mathrm{~s}$ in $120 \mathrm{mins})$ while treatment $2(200 \mathrm{mg} / \mathrm{Kg})$ had a change in PTTT of $0.5843 \mathrm{~s}$ in $30 \mathrm{~min}$ and $4.2215 \mathrm{~s}$ in $120 \mathrm{~min}$. though it 
was also observed that the second treatment had the longest PTTT (6.8343 s) at 120 mins (table 1).

The percentage nociceptive inhibition by the aqueous Pleurotus ostreatus extract was determined by comparing the PTTT of the treatments with the control at each 30 mins. The result in this table depends on the result of the control at the same interval. The difference was attributed to the inhibitory effects of the treatments. From Table 3, results of the treatments at $90 \mathrm{~min}$ were comparatively higher than even the $120 \mathrm{~min}$, not because they had greater expression of anti-nociceptive effects of the extract at $90 \mathrm{~min}$ but the control expressed hypersensitivity to pain at 90 minutes time than the other time in the experiment. After then (that is at 120 minutes) nociceptive receptors lost sensitivity greatly hence PTTT was observed to be the highest in control (table 2 ). The cause of such hypersensitivity at $90 \mathrm{~min}$ and a sharp decline in 120 minute need to be further studied. The treatment groups did not express such hypersensitivity hence having a progressively increase in PTTT (Table 3. Fig 2)

Table 3: Relative Percentage Nociceptive Inhibition by the treatments

\begin{tabular}{lllll}
\hline Treatment & $30 \mathrm{~min}$ & $60 \mathrm{~min}$ & $90 \mathrm{~min}$ & $120 \mathrm{~min}$ \\
\hline Treat $1(100 \mathrm{mg} / \mathrm{Kg})$ & 177.30 & 567.49 & 1279.82 & 571.24 \\
Treat $2(200 \mathrm{mg} / \mathrm{Kg})$ & 150.92 & 734.90 & 2098.17 & 665.54 \\
Treat $3(400 \mathrm{mg} / \mathrm{Kg})$ & 72.393 & 523.53 & 1458.72 & 144.56 \\
Aspirin $(15 \mathrm{mg} / \mathrm{Kg})$ & 463.80 & 574.51 & 1956.88 & 619.17 \\
\hline
\end{tabular}



Fig.1: Average Pain Tolerance Threshold Time (PTTT) (s)

Conclusion: From the result it is clear that aqueous extract of Pleurotus ostreatus demonstrated significant difference in pain tolerance threshold time between the control and the treatment regimes. This suggested that in addition to other beneficial attributes of Pleurotus ostreatus, it also have good antinociceptive properties and if it is used as an antinociceptive agent to replace some of the synthetic antinociceptive drugs, It can have a promising result against different types of pain that are associated with life of the elderly. It was also observed that the extract at $200 \mathrm{mg} / \mathrm{kg}$ expressed the most potent antinociceptive effects.

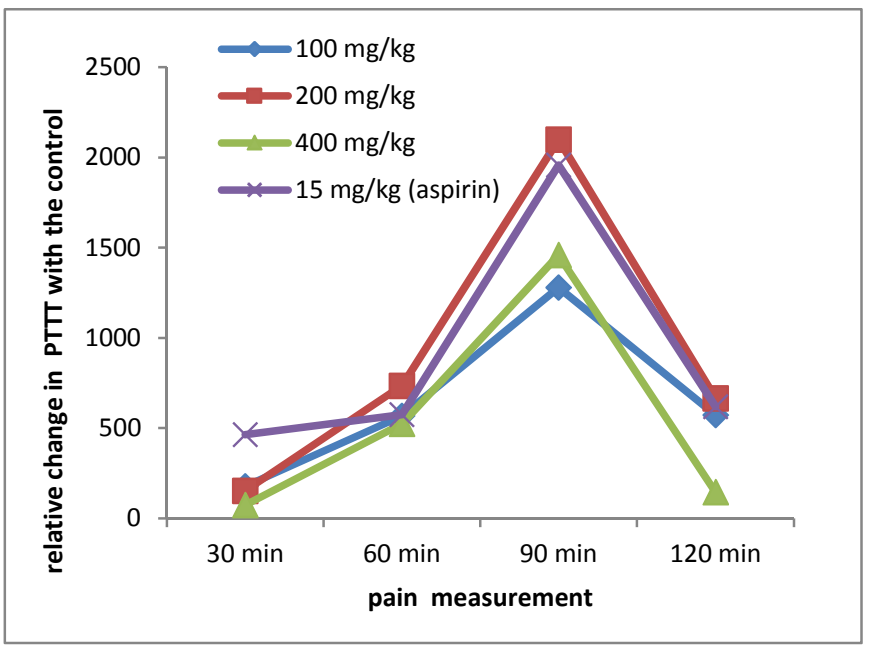

Fig 2: Relative Change in Pain Tolerance threshold Time

\section{REFERENCES:}

Bernston, GG; Cacioppo, JT. (2007). The neuroevolution of motivation. In: Gardner WL, Shah JY. Handbook of Motivation Science. New York: The Guilford Press. ISBN 1-59385-568-0. p. 191.

Brand, PW; Yancey, P. (1997). The gift of pain: why we hurt \& what we can do about it. Grand Rapids, Mich: Zondervan Publ; ISBN 0-310-22144-7.

Ganeshpurkar, A; Bhadoriya, SS; Pardhi, P; Jain, A.P; Rai, G. (2011). In vitro prevention of cataract by Oyster Mushroom Pleurotus florida extract on isolated goat eye lens. Indian J Pharmacol. 43: 667-70.

Ganeshpurkar, A; Bhadoriya, SS; Pardhi, P; Rai, G. (2012). Investigation of anthelmintic potential of 
oyster mushroom Pleurotus florida. Indian $\mathrm{J}$ Pharmacol. 44:539-40.

Jose, A; Ajith TA; Janardhanan KK. (2004). Methanol extract of the oyster mushroom, Pleurotus florida, inhibits inflammation and platelet aggregation. Phytother Res.; 18:43-6.

Lynn, B. (1983). Cutaneous nociceptors ' . In: Winlow W, Holden AV. The neurobiology of pain: Symposium of the Northern Neurobiology Group, held at Leeds on 18 April. Manchester: Manchester University Press; 1984. ISBN 07190-0996-0. p. 106.

Nagasako, EM; Oaklander, AL; Dworkin, RH. (2003). Congenital insensitivity to pain: an update. Pain. 101(3):213-9. doi:10.1016/S03043959(02)00482-7 • . PMID 12583863. .

Nikola, G. (2001). Feeling pain and being in pain " , Oldenburg. ISBN 3-8142-0780-7.

Rollin, BE. (1985) Animal research: a moral science. Talking Point on the use of animals in scientific research. (Draft of the Health Research Extension Act and an animal welfare amendment to the 1985 Food Security Act) EMBO Reports. 2007; 8(6):521-5.
Rollin, BE. (1989). The Unheeded Cry: Animal Consciousness, Animal Pain, and Science. New York: Oxford University Press, pp. xii, 117-118, cited in Carbone 2004, p. 150.

Roy, SK; Das, D; Mondal, S; Maiti, D; Bhunia, B; Maiti TK. (2009). Structural studies of an immunoenhancing water-soluble glucan isolated from hot water extract of an edible mushroom, Pleurotus florida, cultivar Assam Florida. Carbohydr Res.; 344:2596-601.

Vasudewa, NS; Abeytunga, DT; Ratnasooriya, WD. (2007) Antinociceptive activity of Pleurotus ostreatus, an Edible Mushroom in rats. Pharm Biol.; 45:533-40.

Woolf, CJ. (2010). What is this thing called pain?. Journal of Clinical Investigation. 120 (11):37424. doi:10.1172/JCI45178•. PMID $21041955 \cdot$. 